\title{
Comparison between intravenous chemotherapy and intra-arterial chemotherapy for retinoblastoma: a meta- analysis
}

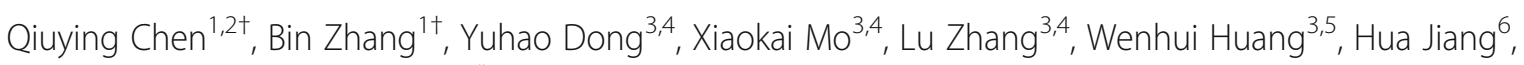
Jiejun $\mathrm{Xia}^{6}$ and Shuixing Zhang ${ }^{1 *}$ (D)

\begin{abstract}
Background: Intravenous chemotherapy (IVC) and intra-arterial chemotherapy (IAC) have become the primary treatments for retinoblastoma; however, some controversy remains over which method is more effective. We conducted a meta-analysis to compare the clinical efficacy of IVC and IAC.

Methods: We systematically searched literature published on PubMed, Embase, and Cochrane Library up to May 2017. Studies containing either IAC or IVC that reported on efficacy were included. The effects estimate was expressed as a pooled rate with 95\% confidence interval (CI), using a fixed-effects or random-effects model.

Results: Twenty-six studies were identified which included 1541 eyes (IAC: 11 trials, 445 eyes; IVC: 16 trials, 1096 eyes). The mean follow-up times were 49.4 months (range, 13.0-105.3 months) for IVC and 21.7 months (range, 8.8-38. 7 months) for IAC. For the International Classification of Intraocular Retinoblastoma (ICRB) grading, the overall success rate was higher with IAC than with IVC (75.7\% [95\%Cl: 65.7\%-83.6\%] vs. 69.5\% [95\%Cl: 51.9\%-82.8\%], $P<0.001)$. The globe salvage with IAC was higher than with IVC in group D eyes $(79.5 \%$ [95\%Cl: $71.8 \%-85.4 \%]$ vs. $55.1 \%$ [95\%Cl: 45.6\%-64.2\%], $\mathrm{P}<0.001)$, but not in groups B (95.8\% [95\%Cl: 57.5\%-99.7\%] vs. 82.5\% [95\%Cl: 58.9\%-94.0\%], $P=0.163), C$ (91.3\% [95\%Cl: 65.9\%-98.3\%] vs. 89.0\% [95\%Cl: 69.0\%-96.7\%], $P=0.212$ ), and $\mathrm{E}$ eyes (51.2\% [95\%Cl: $37.0 \%-65.2 \%]$ vs. 43.2\% [95\%Cl: 18.3\%-72.1\%], $P=0.578)$. IAC and IVC were not significantly different regarding the recurrence and metastasis rates $(15.0 \%$ vs. $15.4 \%, P=0.148$ and $2.7 \%$ vs. $0.6 \%, P=0.194$, respectively). For Reese-Ellsworth (RE) grading, IAC had a higher globe salvage in groups IV (90.9\% [95\%Cl: 56.0\%-98.7\%] vs. $66.3 \%$ [95\%Cl: 32.4\%89.0\%], $P=0.047$ ) and $V$ eyes (83.2\% [95\%Cl: 72.0\%-90.5\%] vs. 59.9\% [95\%Cl: 43.1\%-74.6\%], $P=0.003$ ), but not in group I-III eyes (88.6\% [95\%Cl: 58.3\%-97.7\%] vs. 88.1\% [95\%Cl: 76.6\%-94.4\%], $P=0.244)$. The overall success rate was higher in IAC than in IVC (87.1\% [95\%Cl: 78.1\%-92.7\%] vs. $77.3 \%$ [95\%Cl: 68.1\%-84.4\%], $P=0.033)$.
\end{abstract}

Conclusions: IAC may be superior to IVC for the treatment of retinoblastoma, with a higher overall success rate and higher globe salvage in group $D$ or groups IV and $V$ eyes.

Keywords: Retinoblastoma, Intravenous chemotherapy, Intra-arterial chemotherapy, Meta-analysis

\footnotetext{
*Correspondence: shui7515@126.com

${ }^{\dagger}$ Equal contributors

${ }^{1}$ Department of Radiology, the First Affiliated Hospital, Jinan University,

No.613, Huangpu West Road, Tianhe District, Guangzhou, Guangdong

510627, People's Republic of China

Full list of author information is available at the end of the article
}

(c) The Author(s). 2018 Open Access This article is distributed under the terms of the Creative Commons Attribution 4.0 International License (http://creativecommons.org/licenses/by/4.0/), which permits unrestricted use, distribution, and reproduction in any medium, provided you give appropriate credit to the original author(s) and the source, provide a link to the Creative Commons license, and indicate if changes were made. The Creative Commons Public Domain Dedication waiver (http://creativecommons.org/publicdomain/zero/1.0/) applies to the data made available in this article, unless otherwise stated. 


\section{Background}

Retinoblastoma is the most common intraocular malignancy of childhood (approximately 1/15,000-20,000 live births) and it accounts for $4 \%$ of all pediatric cancers [1]. Two-thirds of all cases of retinoblastoma are diagnosed before the age of two years. All patients with bilateral retinoblastoma and approximately $10 \%-15 \%$ of children with unilateral disease carry a germline mutation which is transmissible to their off spring [2]. In developed countries, the survival rate approaches 98\%; however, due to the limitations of health care in low-income countries, it is much lower at $40 \%[3,4]$. Before the $1990 \mathrm{~s}$, retinoblastoma was mainly treated using enucleation and external beam radiotherapy (EBRT). However, these methods are associated with numerous complications, including loss of vision and severe toxic side effects. Currently, firstline conservative management of retinoblastoma has moved from EBRT and enucleation to intravenous chemotherapy (IVC) or intra-arterial chemotherapy (IAC), consolidated by focal treatment. The therapeutic efficacy of IVC and IAC has received increasing attention.

IVC was first used in 1953 [5]. The standard proto$\mathrm{col}$ is the vincristine-etoposide-carboplatin (VEC) program used as a combination triple-drug therapy, typically performed for six cycles [6]. VEC may yield better results in eyes with advanced cancer when combined with local therapeutic methods. The detrimental effect of IVC on children is worth noting. Since eyes with vitreous or subretinal seeding are less sensitive to IVC treatment, IVC may not perform well in cases of advanced tumors. In addition, IVC is associated with certain adverse reactions: carboplatin is known to cause ototoxicity and etoposide has the potential to cause acute lymphoblastic leukemia.
IAC was first described by Reese and colleagues in 1950 [7]. The technique was pioneered in Japan [8] and was later popularized by Abramson et al. [9]. The procedure involves directly injecting concentrated doses of chemotherapeutic drugs (melphalan, topotecan, or carboplatin) into the ophthalmic artery using a modern microcatheter (Fig. 1), to increase the concentration of chemotherapy drugs 10 - to 30 -fold at the tumor site. Consequently, the concentration of the drugs in the peripheral blood is minimal. Each eye requires an average of three treatment cycles and each cycle is planned at a 4-week interval. Successful treatment is indicated by a decrease in the size of the tumor. Remaining tumors can be eliminated using laser, cryotherapy, or radioactive plaques. Previous studies have reported the efficacy and safety of this approach [10-13]. However, due to the high concentration of the chemical drugs that are used in IAC, local complications are very high. Thus, the issues around improving globe salvage as well as reducing the risk of local complications must be addressed urgently.

At present, both IVC and IAC are first-line treatments for retinoblastoma in the clinical setting. Although IAC has been shown to have excellent therapeutic effects, whether it can replace IVC remains controversial. Some single-arm studies have reported either on IAC or IVC, but only one study compared these two methods in unilateral group D retinoblastoma [14]. Moreover, the outcomes of studies that evaluated success rates of these methods have been discrepant due to the varying quality of the research and the different sources and capacities of the samples. Hence, we performed this study to compare the clinical use of IAC and IVC to identify which method is more effective or to determine if both are necessary for the treatment of retinoblastoma. The improved quality of evidence resulting from this meta-
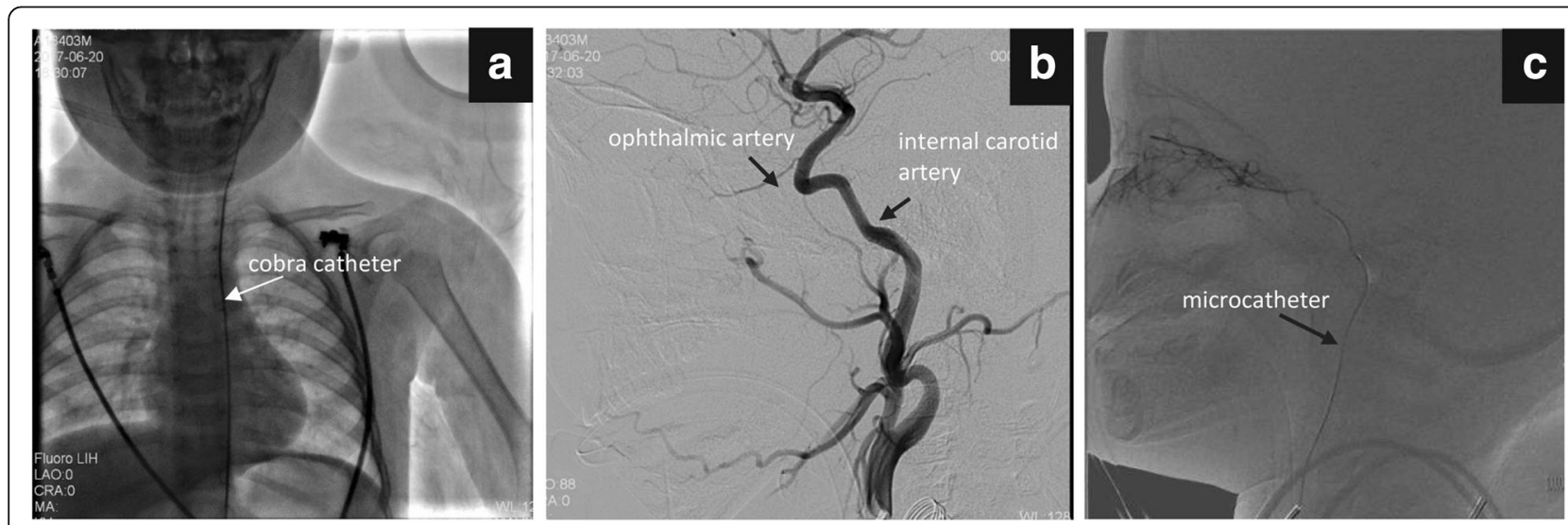

Fig. 1 The technique of intra-arterial chemotherapy (IAC) treatment. a: An arteriogram was performed to indicate the takeoff of the ophthalmic artery from the internal carotid artery. b: Using fluoroscopy and roadmap guidance, the microcatheter selectively catheterized the ophthalmic artery. c: As soon as the microcatheter was in a stable position at the ostium of the ophthalmic artery, then pulse-inject drugs 
analysis is expected to be helpful for doctors in their clinical practice.

\section{Methods}

\section{Search strategy}

PubMed, Embase, and Cochrane Library databases were searched without geographical, publication type, and language restrictions for literature published up to May 2017. The literature was searched by combining Medical Subject Headings (Mesh) and multiple free words. Mesh and free words were combined using a logical 'OR' operator. The results of the Mesh and free words search were combined using a logical 'AND' operator. As the search terms and strategy were not perfect, we also used references from papers to supplement the results. The search strings used in PubMed were as follows:

\#1: (retinoblastoma[mesh]) OR (retinoblastomas) OR (neuroblastoma, retinal) OR (neuroblastomas, retinal) OR (retinalneuroblastoma) OR (retinal neuroblastomas) OR (glioma, retinal) OR (gliomas, retinal) OR (retinal glioma) OR (retinal gliomas) OR (eye cancer, retinoblastoma) OR (glioblastoma, retinal) OR (glioblastomas, retinal) OR (retinal glioblastoma) OR (retinal glioblastomas) OR (sporadic retinoblastoma) OR (retinoblastoma, sporadic) OR (retinoblastomas, sporadic) OR (sporadic retinoblastomas) OR (familial retinoblastoma) OR (familial retinoblastomas) OR (retinoblastoma, familial) OR (retinoblastomas, familial) OR (hereditary retinoblastoma) OR (hereditary retinoblastomas) OR (retinoblastoma, hereditary) OR (retinoblastomas, hereditary),

\#2: (drug therapy [mesh]) OR (drug therapies) OR (therapies, drug) OR (chemotherapy) OR (chemotherapies) OR (pharmacotherapies) OR (therapy, drug) OR (pharmacotherapy),

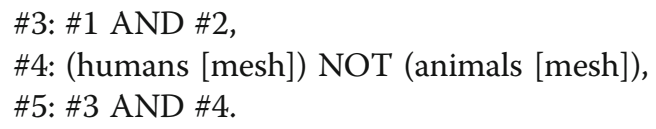

\section{Inclusion criteria}

Two authors (LZ and YHD) reviewed the articles by reading the title, abstract, and full text independently; a third author (XKM) resolved disagreements and recorded the excluded study as well as the reasons for its exclusion. Inclusion criteria were as follows: (1) only IAC or IVC as the primary treatment method (not used in combination); (2) eyes were grouped according to the International Classification of Intraocular Retinoblastoma (ICRB) system, or the Reese-Ellsworth (RE) classification system; (3) studies that provided efficacy data; (4) more than 10 eyes included in a study; and (5) when we encountered multiple publications of the same clinical trial, we selected the latest or most complete publication. We excluded studies if they were published as reviews or case reports.

\section{Classification of retinoblastoma}

Classification of retinoblastoma is necessary to formulate appropriate management strategies and improve predictability of the treatment outcomes. Formerly, RE grading was widely used; however, it was later replaced by ICRB system which included the Philadelphia version and the Children's Hospital Los Angeles (CHLA) version [15]. Therefore, RE grading are mainly reported in earlier articles while ICRB system are mainly reported in articles published in recent years. In order to include valuable data as much as possible, we selected RE grading and ICRB system as the basis for grouping. Fig. 2 shows the fundus photographs of groups A to E eyes.

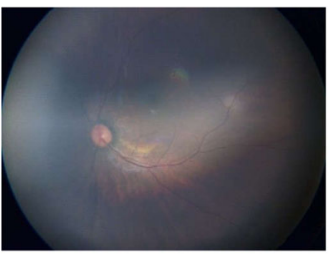

Group A eye

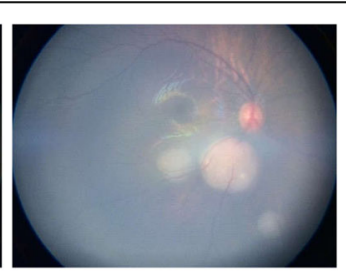

Group B eye

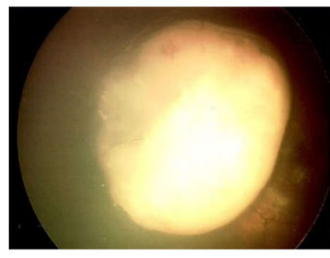

Group C eye

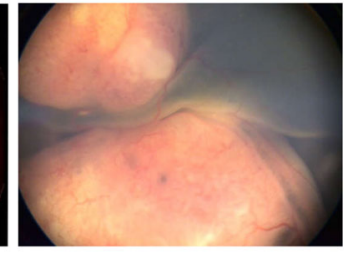

Group D eye

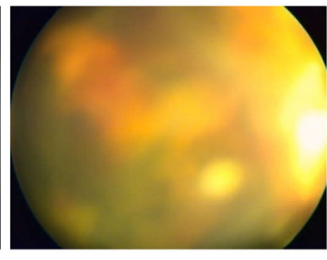

Group E eye

Fig. 2 The fundus photographs of group A-E eyes of retinoblastoma. Group A: Eyes with small discrete tumors away from critical structures; Group B: Eyes with no vitreous or subretinal seeding and discrete retinal tumor of any size or location; Group C: Eyes with only focal vitreous or subretinal seeding and discrete retinal tumors of any size and location; Group D: Eyes with diffuse vitreous or subretinal seeding and/or massive, nondiscrete endophytic or exophytic disease; Group E: Eyes that have been destroyed anatomically or functionally by the tumor 


\section{Data synthesis and analysis}

Meta-analysis was performed for an outcome only if there were appropriate data for at least two single arms in each group. The rates of different groups were used as weighting variables and expressed as a pooled rate with 95\% confidence intervals (CI). We evaluated heterogeneity across studies using $\mathrm{I}^{2}$ statistics, with values of $>25 \%,>50 \%$, and $>75 \%$ representing mild, moderate, and grievous heterogeneity, respectively. If $\mathrm{I}^{2}>50 \%$, a random-effects model was applied in case of statistical heterogeneity, otherwise a fixed-effects model was used. We used the Chi-square test or Fisher's exact test to compare the rates of different groups. A $P$-value of $<0$. 05 was considered statistically significant. Statistical analyses were performed using Comprehensive MetaAnalysis version 2 and SPSS version 16.

\section{Results}

\section{Study characteristics}

One hundred and fifty-six records were selected by searching the databases and citing literature references. After 130 exclusions, 26 articles qualified for the metaanalysis (Fig. 3). The trials included 1402 eyes that received either IAC (11 trials, 445 eyes) or IVC (16 trials, 1096 eyes) as the primary treatment modality up to May 2017. The protocol of IAC was ophthalmic artery chemotherapy infusion under fluoroscopic guidance using melphalan in every case, with additional topotecan and/or carboplatin as necessary (ten trials). The dose was determined by the patient's age. The protocols of IVC included: six-cycle VEC (13 trials), 13-cycle VEC (one trial), six-cycle vincristine-carboplatin (one trial), and six-cycle etoposide-carboplatin (one trial) accompanied by local consolidation therapy (cryotherapy, photocoagulation, thermotherapy, and brachytherapy). Twenty-one studies $[11,14,16-32]$ reported ICRB grading and seven studies [11, 32-37] reported RE grading, two of which reported two gradings. The mean followup time was 49.4 months in IVC and 21.7 months in IAC. Details of eyes in each enrolled trial are listed in Tables 1, 2, and 3. The primary endpoints included globe salvage in each group of eyes and overall success rate. Overall success was defined as avoidance of EBRT or enucleation. The secondary endpoints were recurrence rate, the occurrence of adverse events, tumor metastasis rate, and second malignant neoplasms (SMNs) incidence. The outcomes of the meta-analysis are shown in Additional files 1, 2, 3, and 4.

\section{Primary endpoints}

For ICRB grading, the comparison in group A eyes could not be performed due to the absence of data from IAC. Although no significant differences were observed in the globe salvage rates between IAC and IVC in group B eyes (95.8\% [95\%CI: $57.5 \%-99.7 \%$ ] vs. $82.5 \%$ [95\%CI: $58.9 \%-$ 94.0\%], $P=0.163)$ and group $C$ eyes $(91.3 \%$ [95\%CI:

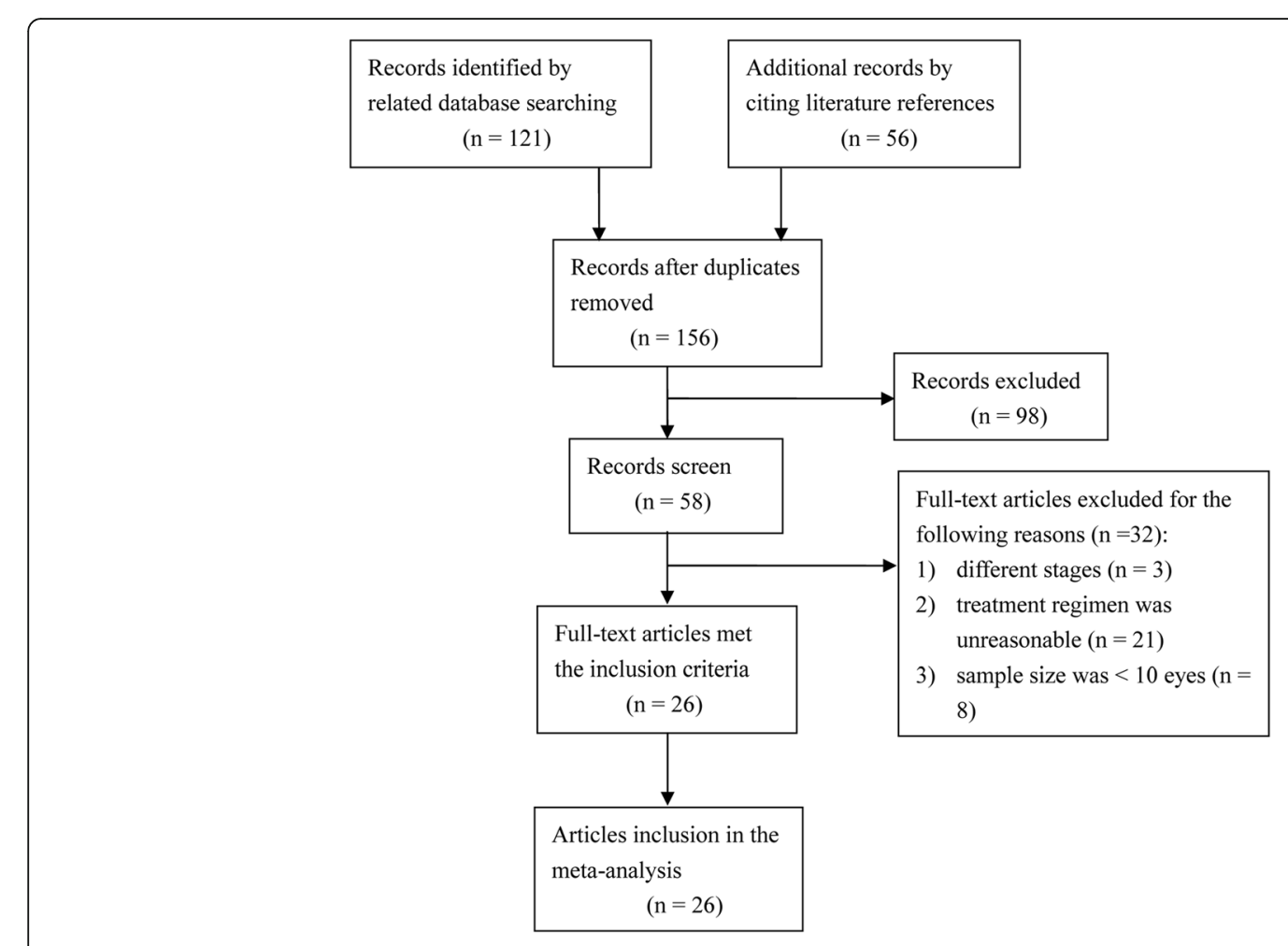

Fig. 3 The literature screening flowchart 


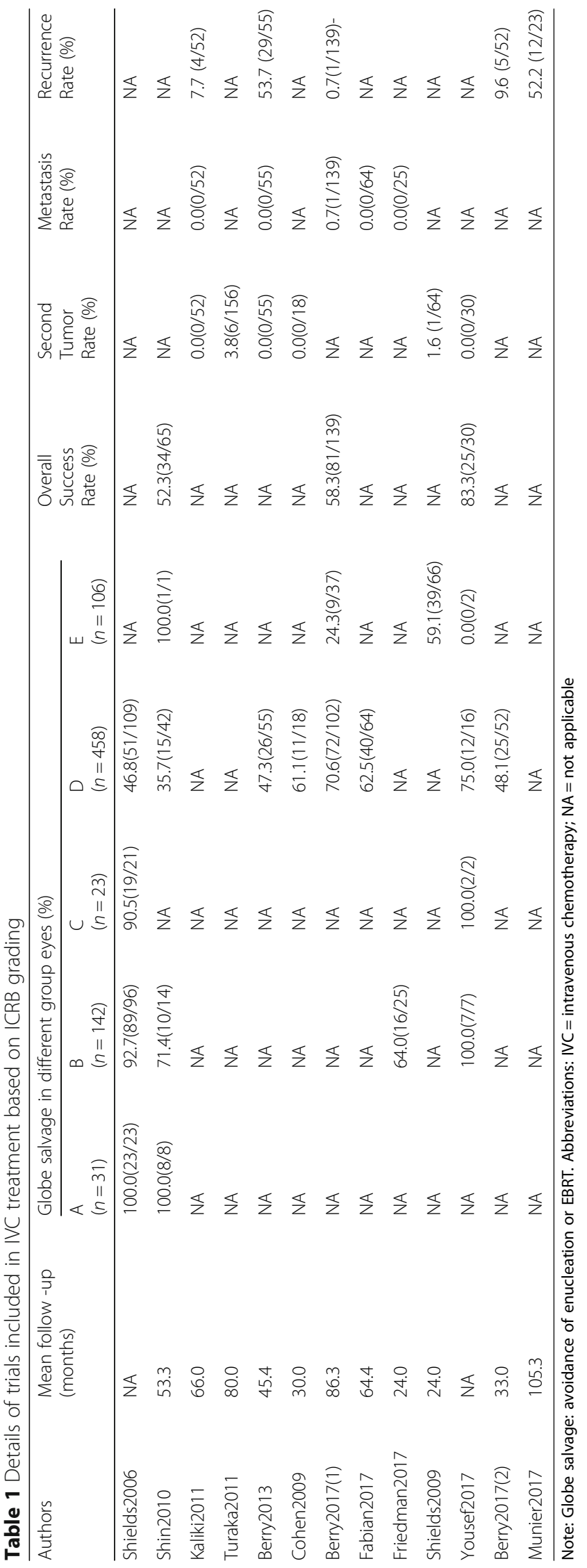




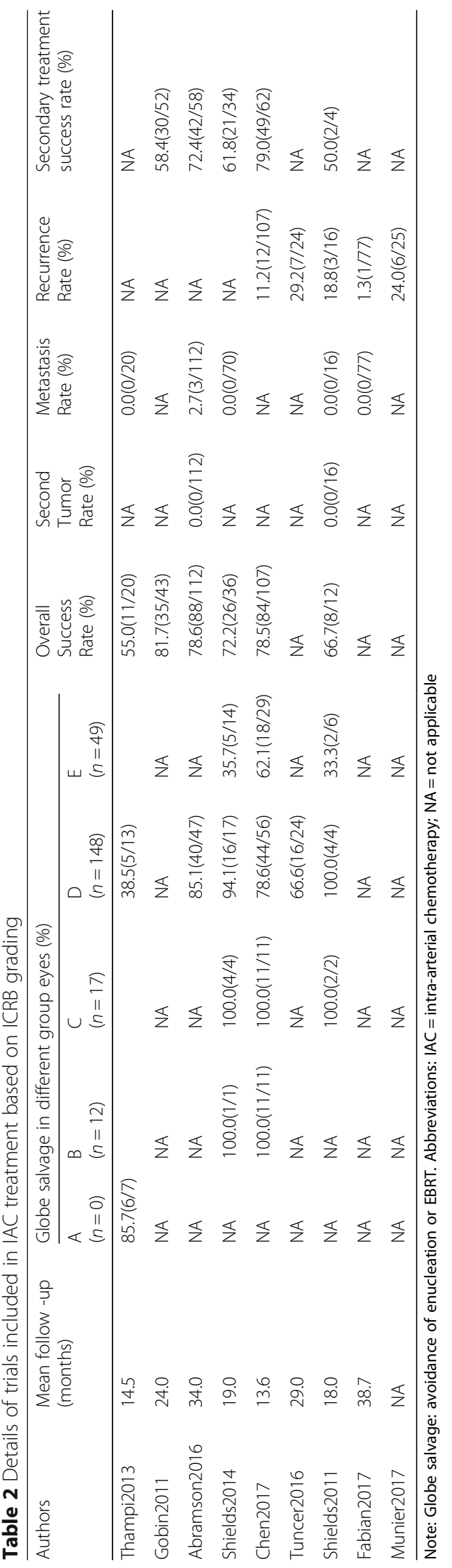


Table 3 Details of trials included in IAC or IVC treatment based on RE grading

\begin{tabular}{|c|c|c|c|c|c|c|}
\hline \multirow[t]{2}{*}{ Authors } & \multirow{2}{*}{$\begin{array}{l}\text { Primary } \\
\text { treatment }\end{array}$} & \multirow{2}{*}{$\begin{array}{l}\text { Mean follow -up } \\
\text { (months) }\end{array}$} & \multicolumn{3}{|c|}{ Globe salvage in different group eyes (\%) } & \multirow{2}{*}{$\begin{array}{l}\text { Overall } \\
\text { success } \\
\text { rate (\%) }\end{array}$} \\
\hline & & & $|-|||$ & IV & V & \\
\hline Gombos2002 & IVC & 33.0 & $84.8(28 / 32)$ & $50(1 / 2)$ & $62.5(5 / 8)$ & $81.0(34 / 42)$ \\
\hline Brichard2002 & IVC & 21.0 & $100.0(12 / 12)$ & NA & $57.1(12 / 21)$ & $72.7(24 / 33)$ \\
\hline Kim2003 & IVC & 13.0 & $85.7(12 / 14)$ & $71.4(5 / 7)$ & $66.7(4 / 6)$ & $77.8(21 / 27)$ \\
\hline Abramson2008 & IAC & 9.0 & NA & NA & $77.8(7 / 9)$ & $77.8(7 / 9)$ \\
\hline Abramson2010 & IAC & 15.0 & $100.0(2 / 2)$ & $100.0(1 / 1)$ & $96.0(24 / 25)$ & $96.4(27 / 28)$ \\
\hline Gobin2011 & IAC & 24.0 & $100.0(8 / 8)$ & $100.0(4 / 4)$ & $80.6(29 / 36)$ & $85.4(41 / 48)$ \\
\hline Shields2011 & $I A C$ & 24.0 & $100.0(2 / 2)$ & $100.0(5 / 5)$ & $83.3(5 / 6)$ & $92.3(12 / 13)$ \\
\hline
\end{tabular}

Note: Globe salvage: avoidance of enucleation or EBRT. Abbreviations: IVC = intravenous chemotherapy; IAC = intra-arterial chemotherapy; NA = not applicable

65.9\%-98.3\%] vs. $89.0 \%$ [95\%CI: $69.0 \%-96.7 \%$ ], $P=0.212$ ), our data suggested that IAC and IVC performed well in terms of globe salvage. The globe salvage rate of IAC was higher than that of IVC in group D eyes $(79.5 \%$ [95\%CI: 71.8\%-85.4\%] vs. $55.1 \%$ [95\%CI: $45.6 \%-64.2 \%$ ], $P<0.001)$, but not in group E eyes (51.2\% [95\%CI: 37.0\%-65.2\%] vs. 43.2\% [95\%CI: $18.3 \%-72.1 \%$ ], $P=0.578$ ). Furthermore, the overall success rate was slightly higher in IAC $(75.7 \%$ [95\%CI: $65.7 \%-83.6 \%$ ] vs. $69.5 \%$ [95\%CI: $51.9 \%-82.8 \%$ ], $P$ $<0.001)$ than in IVC.

For RE grading, IAC had a higher globe salvage rate than IVC in group IV (90.9\% [95\%CI: 56.0\%-98.7\%] vs. 66.3\% [95\%CI: 32.4\%-89.0\%], $P=0.047$ ) and group $\mathrm{V}$ eyes (83.2\% [95\%CI: 72.0\%-90.5\%] vs. 59.9\% [95\%CI: 43. $1 \%-74.6 \%$ ], $P=0.003)$, but not in group I-III eyes $(88.6 \%$ [95\%CI: $58.3 \%-97.7 \%$ ] vs. $88.1 \%$ [95\%CI: 76.6\%-94.4\%], $P=0.244)$. The overall success rate was higher in IAC than in IVC $(87.1 \%$ [95\%CI: $78.1 \%-92.7 \%$ ] vs. $77.3 \%$ [95\%CI: 68.1\%-84.4\%], $P=0.033)$.

\section{Secondary endpoints}

For ICRB grading, five IVC trials (321 eyes) and five IAC trials (249 eyes) reported tumor recurrence. The analysis revealed no difference in the recurrence rate between IAC (15.0\% [95\%CI: 7.3\%-28.4\%], P<0.001) and IVC $(15.4 \%$ [95\%CI: $4.1 \%-43.8 \%$ ], $P=0.022$ ), with a $P$-value of 0.148 . In IVC, metastasis occurred in only one eye [20], whereas it occurred in six eyes in IAC $[29,38]$. However, no evidence supported that IVC had an advantage over IAC $(2.7 \%$ vs. $0.6 \%, P=0.194)$. In a study by Turaka et al. [39], $4 \%(6 / 156)$ of patients with germline retinoblastoma treated with IVC as first-line therapy developed SMNs. These SMNs included osteosarcoma $(n=3)$, tectal glioma $(n=1)$, acute promyelocytic leukemia $(n=1)$, and one patient with both rhabdomyosarcoma (temporal fossa) and conjunctival/orbital malignant melanoma. Shields et al. [25] reported one case of osteosarcoma. However, no SMNs were reported in patients treated with IAC. For RE grading, recurrence occurred in only five eyes (two trials). No tumor metastasis or SMNs was reported.
The details of adverse events of IAC (seven trials) and IVC (nine trials) are listed in Table 4. Adverse events included systemic complications and ocular complications. IAC had more systemic complications than IVC, including neutropenia and infections. Ocular complications were also reported more frequently in IAC, which included vascular injury, spasm, obstruction, and a series of related organ ischemic lesions.

\section{Heterogeneity}

For IAC based on ICRB grading, no statistical heterogeneity was found in globe salvage of group $\mathrm{B}$ eyes $\left(\mathrm{I}^{2}=\right.$ $0 \%, P=0.360)$ and group $C$ eyes $\left(\mathrm{I}^{2}=0 \%, P=0.765\right)$. There was moderate statistical heterogeneity in globe salvage of group D eyes $\left(\mathrm{I}^{2}=26.89 \%, P=0.242\right)$, group $\mathrm{E}$ eyes $\left(\mathrm{I}^{2}=40.19 \%, P=0.188\right)$ as well as in the secondary treatment success rate $\left(\mathrm{I}^{2}=44.19 \%, P=0.127\right)$. However, grievous heterogeneity was found in overall success rate $\left(\mathrm{I}^{2}=52.66 \%, P=0.061\right)$ and recurrence rate $\left(\mathrm{I}^{2}=69.44 \%\right.$, $P=0.011$ ). For IVC based on ICRB grading, we did not observe significant heterogeneity in globe salvage of group $\mathrm{A}$ eyes $\left(\mathrm{I}^{2}=0 \%, P=0.618\right)$ and group $\mathrm{C}$ eyes $\left(\mathrm{I}^{2}=\right.$ $0 \%, P=0.731)$, but there was grievous heterogeneity in groups $\mathrm{B}\left(\mathrm{I}^{2}=77.66 \%, P=0.004\right), \mathrm{D}\left(\mathrm{I}^{2}=72.21 \%, P=0.001\right)$, and $\mathrm{E}$ eyes $\left(\mathrm{I}^{2}=76.75 \%, P=0.005\right)$. High heterogeneity was also found in overall success rate $\left(\mathrm{I}^{2}=84.20 \%, P=0.002\right)$ and recurrence rate $\left(\mathrm{I}^{2}=92.37 \%, P<0.001\right)$. No statistical heterogeneity was found in all groups of $\mathrm{RE}$ grading $\left(\mathrm{I}^{2}=\right.$ $0 \%, P=0.401-0.924)$.

\section{Discussion}

The current commonly used treatments for retinoblastoma include IVC and IAC, along with consolidated therapy based on tumor staging. For ICRB grading, we found a significantly higher globe salvage rate for group $\mathrm{D}$ eyes in patients who received IAC compared with those who received IVC, while no statistical differences were found in groups $\mathrm{A}, \mathrm{B}, \mathrm{C}$, and $\mathrm{E}$ eyes. IAC was associated with a slightly higher overall success rate than IVC. There was no difference in tumor recurrence and 
Table 4 Adverse events of IVC and IAC in the treatment of retinoblastoma

\begin{tabular}{|c|c|c|c|}
\hline Trials & Treatment & Patients & Adverse Events \\
\hline Berry2012 & IVC & 7 & febrile neutropenia \\
\hline Kaliki2011 & IVC & 1 & pneumonia \\
\hline \multirow[t]{3}{*}{ Fabian2017 } & IVC & 6 & choroidal ischaemia \\
\hline & & 4 & retinal detachments \\
\hline & & 6 & nystagmus \\
\hline \multirow[t]{2}{*}{ Friedman2016 } & IVC & 8 & grade 3 or 4 toxicity \\
\hline & & 2 & infections (allergic reaction with urticaria) dehydration) \\
\hline Yousef2017 & IVC & 3 & rhegmatogenous retinal detachment \\
\hline Berry2017 & IVC & 2 & febrile neutropenia \\
\hline Munier2016 & IVC & 3 & occlusive choroidopathy \\
\hline \multirow[t]{4}{*}{ Thampi2013 } & IVC & 6 & infections (fever, acute otitis media, upper) respiratory tract infection) \\
\hline & & 3 & vitreous hemorrhage \\
\hline & & 2 & grade 4 neutropenia \\
\hline & & 1 & cataract \\
\hline \multirow[t]{3}{*}{ Brichard 2002} & IVC & 9 & non-specific gastrointestinal toxicity \\
\hline & & 8 & cytopenias \\
\hline & & 8 & fever \\
\hline \multirow[t]{4}{*}{ Gobin2011 } & IAC & 6 & allergic reaction \\
\hline & & 3 & cataract \\
\hline & & 29 & neutropenia \\
\hline & & 1 & fever \\
\hline \multirow[t]{7}{*}{ Abramson2016 } & IAC & 39 & grade 3 or 4 neutropenia \\
\hline & & 5 & allergy-type reaction \\
\hline & & 4 & grade 3 or 4 thrombocytopenia \\
\hline & & 4 & fever \\
\hline & & 6 & retinal or choroidal vascular occlusions \\
\hline & & 5 & phthisis \\
\hline & & 4 & vitreous hemorrhage \\
\hline \multirow[t]{3}{*}{ Shields2014 } & IAC & 4 & vitreous hemorrhage \\
\hline & & 5 & artery obstruction \\
\hline & & 4 & partial choroidal ischemia \\
\hline Fabian2017 & IAC & 6 & Nystagmus \\
\hline \multirow[t]{4}{*}{ Abramson2008 } & IAC & 3 & lids edema \\
\hline & & 3 & conjunctiva hyperemia \\
\hline & & 1 & radiationlike retinopathy \\
\hline & & 1 & neutropenia \\
\hline \multirow[t]{2}{*}{ Abramson2010 } & IAC & 9 & grade 3 neutropenia \\
\hline & & 1 & grade 4 neutropenia \\
\hline \multirow[t]{3}{*}{ Tuncer2016 } & IAC & 9 & chorioretinal atrophy \\
\hline & & 5 & noted retinal detachment \\
\hline & & 1 & vitreous haemorrhage \\
\hline
\end{tabular}


metastasis rates between IAC and IVC. For RE grading, IAC showed a significant advantage in globe salvage of groups IV and V eyes, but not in group I-III eyes. The overall success rate was higher in IAC than IVC.

The aim of this meta-analysis was to quantitatively merge the congeneric rates of included studies that were searched as thoroughly as possible to enlarge the sample size for a more reliable result. To the best of our knowledge, this is the first meta-analysis to compare the outcomes of IVC and IAC for the treatment of retinoblastoma. We made use of multiple statistical rates to compare IVC and IAC across different staging systems to obtain an objective conclusion.

The outcomes of globe salvage of groups A to $C$ eyes may not be reliable because of the unequal or excessively small number of trials. Overall, IAC had significant advantages over IVC in globe salvage of group D eyes and a better overall success rate. However, in approximately half of the group E eyes, treatment with IAC or IVS was unsuccessful, and the eyes eventually had to be removed. To save more diseased eyes at advanced stages, appropriate treatments should be developed. We will focus on this issue in a future study.

There was no significant difference between IAC and IVC regarding tumor recurrence. Extensive recurrence of subretinal or vitreous seeds was the most common cause of treatment failure which led to final enucleation. Shields et al. $[11,30]$ reported that most recurrences were discovered at the three-year follow-up. In the present study, the follow-up period of patients who received IAC was shorter than three years; therefore, the effect of IAC on tumor recurrence may be over-evaluated.

Some studies have reported adverse events associated with IVC; however, most adverse events would disappear after symptomatic treatment. Rational chemotherapy drug use was essential to reduce the occurrence of adverse events in IVC treatment. In contrast, despite the advantages regarding tumor control, IAC carried a higher risk for potential local complications because of the high concentration of chemical drugs in the eye. The main temporary IACrelated complications that have been reported include eyelid edema, blepharoptosis, forehead hyperemia, and forehead hyperpigmentation, with a mean remission of two weeks to four months [28, 30]. Moreover, IAC-induced vascular events, including vascular injury, spasm, obstruction, and a series of related organ ischemic lesions, deserve attention. Evidence also exists that IAC causes fatal side effects such as stroke or limb ischemia, though they are rare. Most retinal arterial obstructions were found at the one-month follow-up, whereas choroidal vascular atrophy develops slowly and usually takes several months to become apparent [40]. Vascular compromise could lead to poor vision [41], but assessment of vision requires a long follow-up. Therefore, closer visual observation should be recommended for these patients. In addition, the incidence of vascular events can be significantly reduced by precise surgery, careful angiography analysis, and ideal microcatheter placement.

In countries with advanced health care, the incidence of metastasis in children with retinoblastoma is less than $10 \%$ [10]. The risk of metastasis greatly increases with histopathologic evidence of high-risk features. Kaliki et al. [22] reported that metastasis did not occur in any patient classified with non-high-risk retinoblastoma, but that death from metastasis occurred in $4 \%$ of high-risk patients [42]. Besides, patients with heritable retinoblastoma also have an increased risk of SMNs. The most commonly observed SMNs are sarcomas, melanomas, and myelogenous leukemia, as well as cancers of the nasal cavity, orbit, and brain. The cumulative mortality ratio of an SMNs in patients with heritable retinoblastoma to those with non-hereditable retinoblastoma was 22.5:1 at 50 years of age following a diagnosis of retinoblastoma [13]. As for patients treated with IAC, accumulated exposure to irradiation and the use of melphalan may induce germline mutations and lead to SMNs [43, 44]. Concerning patients treated with IVC, etoposide and carboplatin have been shown to increase the risk of SMNs [45-47]. Moreover, the total dose is also an important factor that should be considered when assessing risk. Most patients with SMNs received higher total doses than patients who received normal treatment. However, in all studies of SMNs, a large proportion of the eyes previously or simultaneously received external radiotherapy. Therefore, the occurrence of SMNs was not necessarily due to chemotherapy; radiation therapy may have been responsible. The effect of IAC and IVC on the prevention of SMNs warrants optimism.

This study had some limitations. Firstly, it was based on data from clinical trials which implied the impossibility of excluding the presence of confounding factors, such as the selection of medications, the severity of the condition (unilateral or bilateral disease, tumor diameter and thickness, subretinal fluid, and subretinal or vitreous tumor seeds), and previous therapies received. In addition, because retinoblastoma is a relatively rare disease, the number of eligible trials was not sufficient for a robust analysis. Moreover, the follow-up time for patients who received IAC was shorter (23.9 months) than for those who received IVC (55.6 months), which could bias the results. It was evident that long-term survival rates gradually declined as the follow-up time extended $[19,25,30]$. Consequently, the results of this metaanalysis were preliminary. Further analyses with more eyes and long-term dynamic observations are necessary to refine the results. 


\section{Conclusions}

The results suggested that IAC had advantages in eyes with advanced disease, including groups $\mathrm{D}, \mathrm{IV}$, and $\mathrm{V}$, but not in groups A-C, E, and I-III eyes. The overall success rate was higher in IAC than in IVC. However, there were no significant differences between the two methods regarding tumor recurrence and metastasis rates. Larger sample studies with longer follow-up times are warranted to confirm our findings.

\section{Additional files}

Additional file 1: The outcomes of meta-analysis in intra-arterial chemotherapy based on ICRB grading. (DOCX $244 \mathrm{~kb}$ )

Additional file 2: The outcomes of meta-analysis in intravenous chemotherapy based on ICRB grading. (DOCX $280 \mathrm{~kb}$ )

Additional file 3: The outcomes of meta-analysis in intra-arterial chemotherapy based on RE grading. (DOCX $191 \mathrm{~kb}$ )

Additional file 4: The outcomes of meta-analysis in intravenous chemotherapy based on RE grading. (DOCX $174 \mathrm{~kb}$ )

\section{Abbreviations}

$\mathrm{Cl}$ : Confidence interval; EBRT : External beam radiotherapy; IAC : Intra-arterial chemotherapy; ICRB : The International Classification of Intraocular Retinoblastoma; IVC: Intravenous chemotherapy; Mesh : Medical Subject Headings; RE : Reese-Ellsworth; SMNs : Second malignant neoplasms; VEC : Vincristine, etoposide and carboplatin

\section{Acknowledgements}

We acknowledge the Women's and Children Medical Center of Guangzhou for providing the Figs. 1 and 2 .

\section{Funding}

National Scientific Foundation of China (81571664); the Science and Technology Planning Project of Guangdong Province (2014A020212244, 2016A020216020); the Scientific Research General Project of Guangzhou Science Technology and Innovation Commission (201605110912158); and the General Financial of China Postdoctoral Science Foundation (2016 M600145)

\section{Availability of data and materials}

All data generated or analysed during this study are included in this published article.

\section{Authors' contributions}

QYC and BZ contributed to the conception and design of the study, the analysis and interpretation of data, the revision of the article as well as final approval of the version to be submitted. $L Z, Y H D, W H H$, and XKM participated in the literature screening and data extraction. JJX and $\mathrm{HJ}$ offered guidance and provided figures. All authors read and approved the final version of the manuscript.

\section{Ethics approval and consent to participate}

This meta-analysis was approved by the institutional review board, the need for informed patient consent for inclusion was waived.

\section{Competing interests}

The authors declare that they have no competing interests.

\section{Publisher's Note}

Springer Nature remains neutral with regard to jurisdictional claims in published maps and institutional affiliations.

\section{Author details}

'Department of Radiology, the First Affiliated Hospital, Jinan University, No.613, Huangpu West Road, Tianhe District, Guangzhou, Guangdong 510627, People's Republic of China. ${ }^{2}$ Graduate College, Jinan University, Guangzhou, Guangdong, People's Republic of China. ${ }^{3}$ Department of Radiology, Guangdong General Hospital/Guangdong Academy of Medical Sciences, Guangzhou, Guangdong, People's Republic of China. ${ }^{4}$ Graduate College, Southern Medical University, Guangzhou, Guangdong, People's Republic of China. ${ }^{5}$ School of medicine, South China University of Technology, Guangzhou, Guangdong, People's Republic of China. ${ }^{6}$ Department of Interventional Radiology and Vascular Anomalies, Women's and Children Medical Center, Guangzhou, China.

Received: 29 December 2017 Accepted: 18 April 2018

Published online: 27 April 2018

\section{References}

1. Narang S, Mashayekhi A, Rudich D, Shields CL. Predictors of long-term visual outcome after chemoreduction for management of intraocular retinoblastoma. Clin Exp Ophthalmol. 2012;40:736-42.

2. Rothschild PR, Levy D, Savignoni A, Lumbroso-Le Rouic L, Aerts I, GauthierVillars M, Esteve M, Bours D, Desjardins L, Doz F, Levy-Gabriel C: Familial retinoblastoma: fundus screening schedule impact and guideline proposal. A retrospective study. Eye (Lond) 2011, 25:1555-1561.

3. Canturk S, Qaddoumi I, Khetan V, Ma Z, Furmanchuk A, Antoneli CB, Sultan I, Kebudi R, Sharma T, Rodriguez-Galindo C, et al. Survival of retinoblastoma in less-developed countries impact of socioeconomic and health-related indicators. Br J Ophthalmol. 2010;94:1432-6.

4. MacCarthy A, Birch JM, Draper GJ, Hungerford JL, Kingston JE, Kroll ME, Stiller CA, Vincent TJ, Murphy MF. Retinoblastoma: treatment and survival in great Britain 1963 to 2002. Br J Ophthalmol. 2009;93:38-9.

5. Kupfer C. Retinoblastoma treated with intravenous nitrogen mustard. Am J Ophthalmol. 1953:36:1721-3.

6. Yanik O, Gunduz K, Yavuz K, Tacyildiz N, Unal E. Chemotherapy in retinoblastoma: current approaches. Turk J Ophthalmol. 2015:45:259-67.

7. Reese AB, Hyman GA, Merriam GR Jr, Forrest AW, Kligerman MM. Treatment of retinoblastoma by radiation and triethylenemelamine. AMA Arch Ophthalmol. 1954:53(4):505-13.

8. Yamane T, Kaneko A, Mohri M. The technique of ophthalmic arterial infusion therapy for patients with intraocular retinoblastoma. Int J Clin Oncol. 2004:9:69-73.

9. Abramson DH, Marr BP, Dunkel IJ, Brodie S, Zabor EC, Driscoll SJ, Gobin YP. Intra-arterial chemotherapy for retinoblastoma in eyes with vitreous and/or subretinal seeding: 2-year results. Br J Ophthalmol. 2012;96:499-502.

10. Abramson DH, Fabius AW, Issa R, Francis JH, Marr BP, Dunkel IJ, Gobin YP. Advanced unilateral retinoblastoma: the impact of ophthalmic artery chemosurgery on enucleation rate and patient survival at MSKCC. PLOS One. 2015:10:e0145436.

11. Shields CL, Bianciotto CG, Jabbour P, Ramasubramanian A, Lally SE, Griffin GC, Rosenwasser R, Shields JA. Intra-arterial chemotherapy for retinoblastoma: report no. 1, control of retinal tumors, subretinal seeds, and vitreous seeds. Arch Ophthalmol. 2011:129:1399-406.

12. Yu CL, Tucker MA, Abramson DH, Furukawa K, Seddon JM, Stovall M, Fraumeni JF Jr, Kleinerman RA. Cause-specific mortality in long-term survivors of retinoblastoma. J Natl Cancer Inst. 2009;101:581-91.

13. Marees T, Moll AC, Imhof SM, de Boer MR, Ringens PJ, van Leeuwen FE. Risk of second malignancies in survivors of retinoblastoma: more than 40 years of follow-up. J Natl Cancer Inst. 2008;100:1771-9.

14. Munier FL, Mosimann P, Puccinelli F, Gaillard MC, Stathopoulos C, Houghton S, Bergin C, Beck-Popovic M. First-line intra-arterial versus intravenous chemotherapy in unilateral sporadic group $D$ retinoblastoma: evidence of better visual outcomes, ocular survival and shorter time to success with intra-arterial delivery from retrospective review of 20 years of treatment. $\mathrm{Br} J$ Ophthalmol. 2017;101:1086-93.

15. Novetsky DE, Abramson DH, Kim JW, Dunkel IJ. Published international classification of retinoblastoma (ICRB) definitions contain inconsistencies-an analysis of impact. Ophthalmic Genet. 2009:30:40-4.

16. Yousef YA, Nazzal RM, Khalil MB, Deebajah R, Mehyar M, Hajja S, Mohammad M, Al Jabary R, Jaradat I, Sultan I, Al Nawaiseh I. Management outcome(s) in eyes with retinoblastoma previously inadequately treated 
with systemic chemotherapy alone without focal therapy. Oman $J$ Ophthalmol. 2017;10:70-5.

17. Friedman DL, Krailo M, Villaluna D, Gombos D, Langholz B, Jubran R, Shields C, Murphree L, O'Brien J, Kessel S, et al. Systemic neoadjuvant chemotherapy for group B intraocular retinoblastoma (ARET0331): a report from the Children's oncology group. Pediatr Blood Cancer. 2017;64

18. Fabian ID, Stacey AW, Johnson KP, Onadim Z, Chowdhury T, Duncan C, Reddy MA, Sagoo MS. Primary intravenous chemotherapy for group D retinoblastoma: a 13-year retrospective analysis. Br J Ophthalmol. 2017; 101:82-8.

19. Berry JL, Shah S, Bechtold M, Zolfaghari E, Jubran R, Kim JW. Long-term outcomes of group $D$ retinoblastoma eyes during the intravitreal melphalan era. Pediatr Blood Cancer. 2017:64

20. Berry JL, Kogachi K, Aziz HA, McGovern K, Zolfaghari E, Murphree AL, Jubran R, Kim JW. Risk of metastasis and orbital recurrence in advanced retinoblastoma eyes treated with systemic chemoreduction versus primary enucleation. Pediatr Blood Cancer. 2017;64

21. Berry JL, Jubran R, Kim JW, Wong K, Bababeygy SR, Almarzouki H, Lee TC, Murphree AL. Long-term outcomes of group D eyes in bilateral retinoblastoma patients treated with chemoreduction and low-dose IMRT salvage. Pediatr Blood Cancer. 2013;60:688-93.

22. Kaliki S, Shields CL, Shah SU, Eagle RC Jr, Shields JA, Leahey A. Postenucleation adjuvant chemotherapy with vincristine, etoposide, and carboplatin for the treatment of high-risk retinoblastoma. Arch Ophthalmol. 2011;129:1422-7.

23. Shin JY, Kim JH, Yu YS, Khwarg SI, Choung HK, Shin HY, Ahn HS. Eyepreserving therapy in retinoblastoma: prolonged primary chemotherapy alone or combined with local therapy. Korean J Ophthalmol. 2010;24: 219-24.

24. Shields CL, Ramasubramanian A, Thangappan A, Hartzell K, Leahey A, Meadows AT, Shields JA. Chemoreduction for group E retinoblastoma: comparison of chemoreduction alone versus chemoreduction plus lowdose external radiotherapy in 76 eyes. Ophthalmology. 2009;116:544551.e541.

25. Cohen VM, Kingston J, Hungerford JL. The success of primary chemotherapy for group D heritable retinoblastoma. Br J Ophthalmol. 2009; 93:887-90.

26. Shields CL, Mashayekhi A, Au AK, Czyz C, Leahey A, Meadows AT, Shields JA. The international classification of retinoblastoma predicts chemoreduction success. Ophthalmology. 2006;113:2276-80.

27. Chen M, Jiang H, Zhang J, Shen G, Jiang Y, Li H, Liu Z. Outcome of intraarterial chemotherapy for retinoblastoma and its influencing factors: a retrospective study. Acta Ophthalmol. 2017;95:613-8.

28. Tuncer S, Sencer S, Kebudi R, Tanyildiz B, Cebeci Z, Aydin K. Superselective intra-arterial chemotherapy in the primary management of advanced intraocular retinoblastoma: first 4-year experience from a single institution in Turkey. Acta Ophthalmol. 2016;94:e644-51.

29. Abramson DH, Daniels AB, Marr BP, Francis JH, Brodie SE, Dunkel IJ, Gobin YP. Intra-arterial chemotherapy (ophthalmic artery chemosurgery) for group D retinoblastoma. PLoS One. 2016;1::e0146582.

30. Shields CL, Manjandavida FP, Lally SE, Pieretti G, Arepalli SA, Caywood EH, Jabbour P, Shields JA. Intra-arterial chemotherapy for retinoblastoma in 70 eyes: outcomes based on the international classification of retinoblastoma. Ophthalmology. 2014;121:1453-60.

31. Thampi S, Hetts SW, Cooke DL, Stewart PJ, Robbins E, Banerjee A, Dubois SG, Char D, Halbach V, Matthay K. Superselective intra-arterial melphalan therapy for newly diagnosed and refractory retinoblastoma: results from a single institution. Clin Ophthalmol. 2013;7:981-9.

32. Gobin YP, Dunkel IJ, Marr BP, Brodie SE, Abramson DH. Intra-arterial chemotherapy for the management of retinoblastoma: four-year experience. Arch Ophthalmol. 2011;129:732-7.

33. Abramson DH, Dunkel IJ, Brodie SE, Kim JW, Gobin YP. A phase I/II study of direct intraarterial (ophthalmic artery) chemotherapy with melphalan for intraocular retinoblastoma initial results. Ophthalmology. 2008;115:13981404, 1404.e1391.

34. Kim JH, Yu YS, Khwarg SI, Choi HS, Shin HY, Ahn HS. Clinical result of prolonged primary chemotherapy in retinoblastoma patients. Korean J Ophthalmol. 2003;17:35-43.

35. Gombos DS, Kelly A, Coen PG, Kingston JE, Hungerford JL. Retinoblastoma treated with primary chemotherapy alone: the significance of tumour size, location, and age. Br J Ophthalmol. 2002;86:80-3.
36. Brichard B, De Bruycker JJ, De Potter P, Neven B, Vermylen C, Cornu G Combined chemotherapy and local treatment in the management of intraocular retinoblastoma. Med Pediatr Oncol. 2002;38:411-5.

37. Abramson DH, Dunkel IJ, Brodie SE, Marr B, Gobin YP. Superselective ophthalmic artery chemotherapy as primary treatment for retinoblastoma (chemosurgery). Ophthalmology. 2010;117:1623-9.

38. Fabian ID, Naeem Z, Stacey AW, Chowdhury T, Duncan C, Reddy MA, Sagoo MS. Long-term visual acuity, strabismus, and nystagmus outcomes following multimodality treatment in group D retinoblastoma eyes. Am J Ophthalmol. 2017;179:137-44.

39. Turaka K, Shields CL, Meadows AT, Leahey A. Second malignant neoplasms following chemoreduction with carboplatin, etoposide, and vincristine in 245 patients with intraocular retinoblastoma. Pediatr Blood Cancer. 2012;59: $121-5$.

40. Shields CL, Bianciotto CG, Jabbour P, Griffin GC, Ramasubramanian A, Rosenwasser R, Shields JA. Intra-arterial chemotherapy for retinoblastoma: report no. 2, treatment complications. Arch Ophthalmol. 2011;129:1407-15.

41. Shields CL, Fulco EM, Arias JD, Alarcon C, Pellegrini M, Rishi P, Kaliki S, Bianciotto CG, Shields JA. Retinoblastoma frontiers with intravenous, intraarterial, periocular, and intravitreal chemotherapy. Eye (Lond). 2013;27:253-64.

42. Kaliki S, Shields CL, Rojanaporn D, Al-Dahmash S, McLaughlin JP, Shields JA, Eagle RC Jr. High-risk retinoblastoma based on international classification of retinoblastoma: analysis of 519 enucleated eyes. Ophthalmology. 2013;120: 997-1003.

43. Suzuki S, Yamane T, Mohri M, Kaneko A. Selective ophthalmic arterial injection therapy for intraocular retinoblastoma: the long-term prognosis. Ophthalmology. 2011;118:2081-7.

44. Ramot $Y$, Amir G, Willenz EP, Nyska A. Foreign-body granulomas within intramyocardial arteries in a transcoronary safety assessment in pigs. Toxicol Pathol. 2008:36:385-7.

45. Travis LB, Holowaty EJ, Bergfeldt K, Lynch CF, Kohler BA, Wiklund T, Curtis $R E$, Hall $P$, Andersson M, Pukkala $E$, et al. Risk of leukemia after platinumbased chemotherapy for ovarian cancer. N Engl J Med. 1999;340:351-7.

46. Smith MA, Rubinstein L, Ungerleider RS. Therapy-related acute myeloid leukemia following treatment with epipodophyllotoxins: estimating the risks. Med Pediatr Oncol. 1994;23:86-98.

47. Pedersen-Bjergaard J, Rowley JD. The balanced and the unbalanced chromosome aberrations of acute myeloid leukemia may develop in different ways and may contribute differently to malignant transformation. Blood. 1994:83:2780-6.

\section{Ready to submit your research? Choose BMC and benefit from:}

- fast, convenient online submission

- thorough peer review by experienced researchers in your field

- rapid publication on acceptance

- support for research data, including large and complex data types

- gold Open Access which fosters wider collaboration and increased citations

- maximum visibility for your research: over $100 \mathrm{M}$ website views per year

At BMC, research is always in progress.

Learn more biomedcentral.com/submissions 